\title{
A Visualized Analysis of the Research Current Hotspots and Trends on Innovation Chain Based on the Knowledge Map
}

\author{
Yarui Gao ${ }^{1,2, *}$, Runhui Lin ${ }^{2,3}$ and Yanhong $\mathrm{Lu}^{2}$ \\ 1 Business School, Sias University, Zhengzhou 451150, China \\ 2 Business School, Nankai University, Tianjin 300071, China; linrh@nankai.edu.cn (R.L.); \\ luyanhong@mail.nankai.edu.cn (Y.L.) \\ 3 China Academy of Corporate Governance, Tianjin 300071, China \\ * Correspondence: 11573@sias.edu.cn
}

check for updates

Citation: Gao, Y.; Lin, R.; Lu, Y. A Visualized Analysis of the Research Current Hotspots and Trends on Innovation Chain Based on the Knowledge Map. Sustainability 2022, 14, 1708. https://doi.org/10.3390/ su14031708

Academic Editors: Antonio Messeni Petruzzelli and Lorenzo Ardito

Received: 5 November 2021 Accepted: 24 January 2022

Published: 1 February 2022

Publisher's Note: MDPI stays neutral with regard to jurisdictional claims in published maps and institutional affiliations.

Copyright: () 2022 by the authors Licensee MDPI, Basel, Switzerland. This article is an open access article distributed under the terms and conditions of the Creative Commons Attribution (CC BY) license (https:/ / creativecommons.org/licenses/by/ $4.0 /)$.

\begin{abstract}
The continued increase in global trade protectionism, refinement of labor division, high innovation cost, and development of information technology have led to many enterprises actively being engaged in innovation to improve their national economic competitiveness. Although significant research has been carried out on this by numerous academic institutions, little is known about innovation trends in Chinese enterprises. In the existing methods of literature research, the scientific knowledge map, which, based on bibliometrics, is an effective tool for management knowledge, can visually describe the knowledge resources and their carriers under the state of time series and provides a new way for literature analysis. In this paper, the CiteSpace tool was used to map knowledge domains. A total of 459 and 5645 studies published between 2010 and 2020 were downloaded from the CNKI and Web of Science databases. By analyzing the keywords "co-occurrence matrix", "author cooperation networks", and "high-frequency cited literatures", we found the differences of the research current, hotspots, and trends both in China and the world, but we were not limited to these. The research results are as follows: In China: (1) There were 759 nodes in the map of key authors, which shows that innovation chain research in China is still in the early stages. In addition, the layout of author nodes was relatively scattered while density was low; therefore, it was hard to form clusters. There is a need to strengthen academic cooperation to improve research on innovation chains. (2) From the keyword network analysis map of the innovation chain, we found that the Chinese research hotspots were: innovation chain, industrial chain, collaborative innovation, scientific and technological innovation, innovation-driven, technological innovation, strategic emerging industries, innovation ecosystem, and integration of industry and education, among other fields. In the world: (1) Most academic studies on the innovation chain have been published in different fields; these journals are about production, operation, management science, and economy, among others. These findings show that the innovation chain has received attention from multiple disciplines, and, therefore, it belongs to an interdisciplinary research field. Studies from different fields have analyzed the innovation chain from their own research perspectives. Therefore, current research outcomes on the innovation chain are difficult to unify. (2) The most important authors and key studies were analyzed. According to the co-citation map, studies on the "innovation chain" with high co-citation frequencies were not studies on the innovation chain but had the innovation chain as a theme or a concept without in-depth research on the innovation chain. (3) Through co-citation and cluster analysis of keywords, we found that international studies on the "innovation chain" are more focused on the global value chain, blockchain technology, strategic analysis, sustainable development, and absorptive capacity among other fields. Research frontier themes were mainly communication technology, continuous operation management, technological change, ecological innovation, supply chain integration, Industry 4.0, logistics innovation, nanotechnology, circular economy, and supply chain innovation, among other fields. Therefore, international scholars focus more on: technological issues related to innovation, using advanced communication technology, blockchain technology, and nanotechnology to improve innovation abilities. Moreover, they insist on sustainable development in the process of innovation, advocating for green innovation and ecological innovation. Finally, results of the visualization show that current research is mainly focused on innovation, not the innovation
\end{abstract}


chain. Therefore, experts in this field should pay more attention to the study of structural stability and knowledge mobility of the innovation chain.

Keywords: innovation chain; hotspots; visualization tools; knowledge mapping

\section{Introduction}

International competition and trade protectionism have seriously affected the stability of the global industrial chain. For China, many industries have been affected. Particularly various "KEY" technologies have made some industries in China to be very passive; however, enterprises with complete industrial and innovation chains have not been affected, such as Huawei. Therefore, to survive in the complex internationally competitive environment, China's enterprises should make full use of various resources to build complete and effective innovation chains. At the 40th Anniversary Celebration Conference of Shenzhen Special Economic Zone in October 2020, President Xi said, "We should unswervingly implement the innovation-driven development strategy, cultivate new kinetic energy, enhance new potential energy, and build a highland of science and technology and industrial innovation with global influence. It is necessary to deploy innovation chains around the industrial chain, layout the industrial chain around the innovation chain, prospect the layout of strategic emerging industries, cultivate and develop future industries, and develop digital economy. It is necessary to increase investment in basic research and applied basic research, give full play to the advantages of deep integration of industry, university and research, and actively integrate into the global innovation network." His sentiments emphasize the significance of complete innovation chains to Chinese industrial upgrade and sustainable economic development.

With the support of the state and enterprises, academia has performed various studies on the innovation chain from different angles and to varying degrees. However, despite these studies, a complete set of knowledge system has not been formed. To elucidate on the innovation chain, it is necessary to accurately analyze the current research hotspots and trends in this field. There is a need to establish mechanisms to effectively "search" and "interpret" a large number of documents. In the scientific knowledge map and graph, "look" involves two steps: "search" and "interpretation". In research, expected information is often found to be far less valuable than unexpected information because the latter implies change and is likely to indicate the emergence of new things. Therefore, it is important to establish unusual points through visual maps and to analyze correlations between these unusual points. The CiteSpace design is based on Kuhn's scientific development model theory, Price's scientific frontier theory, structural hole theory of social network analysis, information foraging theory of scientific communication, and discrete and reorganization theory of knowledge units. The significance of these theoretical bases lies in strengthening map and graph interpretability, rationality, and correctness. By interpreting the scientific knowledge map and graph, interpretation of the current situation in this research field and prediction of future prospects can be realized.

As the country and enterprises attach great importance to the innovation chain, academia has conducted a lot of research on it. However, studies on innovation chains have not yet formed a complete set of knowledge system; therefore, there is a need for accurate analysis of the current status of the research in this field to discover hotspots and trends [1].

Based on studies on the innovation chain from 2010 to 2020 in the CNKI and Web of Science databases, we used CiteSpace to analyze and summarize the distribution of authoritative journals on the innovation chain in the past 10 years. The knowledge base in the field of innovation chain, scientific research hotspots, and scientific research frontiers were identified through scientific knowledge mapping. 


\section{Data Sources and Experimental Methods}

\subsection{Data Sources}

Studies on innovation chain knowledge map were obtained by the retrieval method of topic and theme co-citation with reference to the book CiteSpace: Scientific Text Mining and Visualization, edited by Jie li and Chaomei Chen, and by conducting several experiments and comparisons. Chinese studies were obtained from CNKI: SCI, core Journals of Peking University, and CSSCI. A fuzzy search was conducted on the theme of "innovation chain" from 2010 to 2020, and we obtained 459 publications. International studies were obtained from WOS (Web of Science), with "Innovation Chain" as the theme. The included studies were articles and reviews published from 2010 to 2020 in the English language. Through these searches, we obtained a total of 5645 publications. The 459 and 5645 publications were standardized, and literature co-citation analysis was conducted using CiteSpace.V.5.7R2 (64-bit) software. The Top50 \30 (threshold TOP50 and TOP30) cited studies in each time interval were screened. The time slice was set as 1 year, and the co-citation network structure was established.The Parameter setting and co-cited network structure of CNKI and WOS was shown in Tables 1 and 2.

Table 1. Parameter setting and co-cited network structure of CNKI.

\begin{tabular}{ccccc}
\hline Time & Threshold & Space & Nodes & Links/All \\
\hline 2010 & Top50 & 69 & 31 & $29 / 29$ \\
2011 & Top50 & 77 & 37 & $45 / 46$ \\
2012 & Top50 & 104 & 37 & $45 / 49$ \\
2013 & Top50 & 73 & 31 & $25 / 25$ \\
2014 & Top50 & 112 & 40 & $35 / 35$ \\
2015 & Top50 & 106 & 41 & $45 / 45$ \\
2016 & Top50 & 181 & 48 & $61 / 64$ \\
2017 & Top50 & 130 & 43 & $35 / 40$ \\
2018 & Top50 & 108 & 40 & $46 / 46$ \\
2019 & Top50 & 212 & 51 & $66 / 76$ \\
2020 & Top50 & 314 & 63 & $102 / 104$ \\
\hline
\end{tabular}

Table 2. Parameter setting and co-cited network structure of WOS.

\begin{tabular}{ccccc}
\hline Time & Threshold & Space & Nodes & Links/All \\
\hline 2010 & Top30 & 4111 & 55 & $165 / 177$ \\
2011 & Top30 & 4128 & 34 & $59 / 59$ \\
2012 & Top30 & 5397 & 56 & $168 / 189$ \\
2013 & Top30 & 6221 & 57 & $171 / 307$ \\
2014 & Top30 & 6430 & 31 & $79 / 104$ \\
2015 & Top30 & 7888 & 51 & $153 / 275$ \\
2016 & Top30 & 11125 & 40 & $112 / 146$ \\
2017 & Top30 & 13708 & 38 & $114 / 230$ \\
2018 & Top30 & 18402 & 40 & $120 / 154$ \\
2019 & Top30 & 22602 & 40 & $120 / 224$ \\
2020 & Top30 & 33526 & 36 & $108 / 202$ \\
\hline
\end{tabular}

\subsection{Experimental Methods}

We used the Information Visualization tool in Citespace.V.5.7R2 (64-bit) for analysis. We analyzed the co-citations and evaluated knowledge clustering and distribution in the citation space. Because it presents the structure, law, and distribution of scientific knowledge through visualization, the analyzed graph is referred to as a "scientific knowledge graph".

Research fields can be conceptualized based on research fronts $\Psi(t)$ to basic knowledge $\Omega(t)$ time mapping $\Phi(t)$, namely $\Phi(t): \Psi(t) \rightarrow \Omega(t)$. CiteSpace has the ability to identify and display new trends and changes in research topics over time in $\Phi(t) . \Psi(\mathrm{T})$ is a set of terms that are closely associated with new trends and mutations at time $\mathrm{T}$, and these terms are 
referred to as frontier terms. $\Omega(t)$ consists of a large number of articles cited by articles with leading terms, and the relationship between them is summarized as follows [2]:

$$
\begin{aligned}
& \Phi(t): \Psi(t) \rightarrow \Omega(t) \\
& \Psi(t)=\left\{\text { term } \backslash \text { term } \in S_{\text {Title }} \cup S_{\text {Abstract }} \cup S_{\text {descriptior }} \cup S_{\text {indentifier }} \wedge \text { IsHotTopic }(\text { term }, t)\right\} . \\
& \Omega(t)=\left\{\text { article } \backslash \text { term } \in \Psi(\mathrm{t}) \wedge \text { term } \in \text { article }_{0} \wedge \text { article } \text { terticle }_{0} \rightarrow\right. \text { article } \\
& \text { In the formula, } S_{\text {Title }} \text { refers to a series of title terms, IsHotTopic }(\text { term, } t) \text { refers to }
\end{aligned}
$$
Boolean function, and article $_{0} \rightarrow$ article refers to article $_{0}$ cites article.

CiteSpace has three algorithms for calculating the strength of connections in a network, namely Cosine, Jaccard, and Dice. In this paper, the software used the acquiescent Cosine algorithm:

$$
\text { Cosine }\left(C_{i j}, S_{i j}, S_{j}=\frac{c_{i j}}{\sqrt{s_{i} S_{j}}}\right)
$$

The Cosine range was 0 to 1 , where $C_{i j}$ represents co-occurrence times of $i$ and $j, s_{i}$ represents the occurrence frequency of $i$, and $s_{j}$ represents the occurrence frequency of $j$.

\section{Data Analysis and Results}

\subsection{The Co-Author Network of China}

First, 459 publications downloaded by CNKI were converted and imported into CiteSpace.V.5.7R2. Due to limitations of the CNKI data format, only co-occurrence and cluster were analyzed. Figure 1 shows that: node $\mathrm{N}=759, \mathrm{E}=693$, Density $=0.0024$. In China, many scholars are involved in innovation chain studies. Small nodes mean that each scholar did not have many publications on the innovation chain while large nodes represent high-yield authors, who were Jie Zhang, Hongqi Wang, Chao Wang, Haiyun $\mathrm{Xu}$, Zhibiao Liu, Shu Fang, Jianlong Wu, Ping Li, Xuejun Lin, Zhong Yang, and Jie Li, who had 10 related publications.

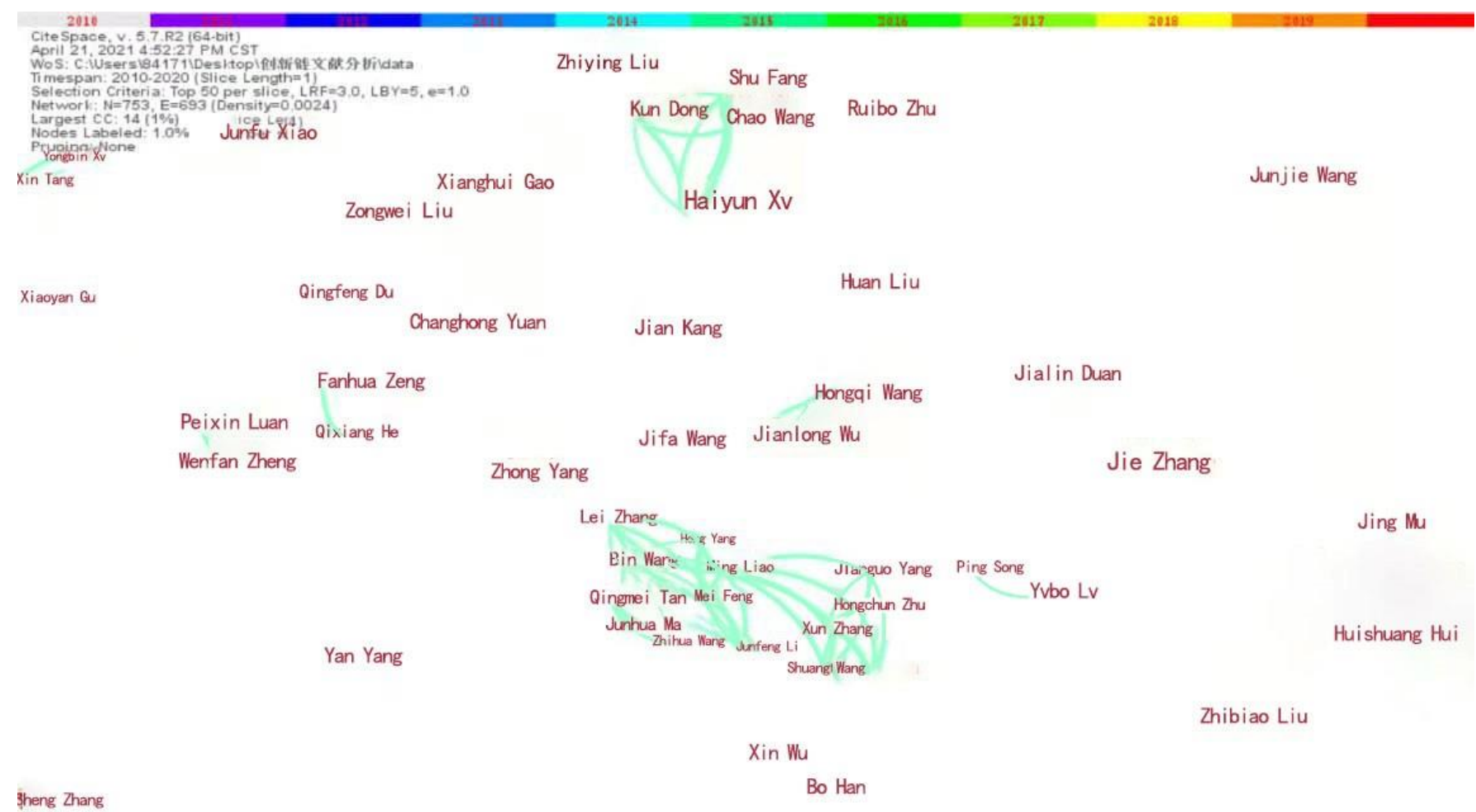

Figure 1. Author co-occurrence map of domestic innovation chain. 
As a new field in China, there is still a lot of room for improvement with regard to studies on innovation chains. In addition, the layout of authors' nodes is relatively scattered, and there is little cooperation among them. Through cluster analysis, major scholars, such as Qingmei Tan, Min Liao, Bin Wang, and Hong Yang only formed a cluster under the theme of "collaborative innovation".

Through detailed analysis of the nodes, the paper by Jie Zhang [3] —“Potential growth rate of structural Economy: Theoretical reconstruction, overall judgment and reform direction" - had the highest co-citation index. This paper reports that institutional resistance, demand-side structural lock, ownership structure imbalance, innovation chain distortion imbalance, financial structure transformation stagnation, talent supply structure distortion, and other factors are associated with the slow pace of supply-side structural adjustment, which inhibits improvement of the potential growth rate of China's structural economy. The publication by Hongqi Wang [4] - "A Review and Prospect of the Research on the Integration of Industrial Innovation Chain and Service Chain" - was the second most co-cited. This paper summarizes and sorts out related studies in this field with regards to function and structure of the innovation chain, evolution law and mode, operation mode and efficiency, integration and reconstruction, and service chain, sci-tech service system, and sci-tech intermediary and service platform. Chao Wang's [5] "Analysis framework and Application of Industrial competitive Intelligence based on innovation chain: A case study of Domestic genetic engineering vaccine industry", for example, introduced the theory of innovation chain, industry competitive intelligence analysis based on the whole process of innovation activities, technological and industrial innovations, and qualitative and quantitative analysis. Haiyun Xu [6] — "Research on the demand and Service Strategy of industrial competitive Intelligence under the background of innovationdriven Development-proposed that service strategy of industrial competitive intelligence based on the industrial innovation chain can meet the demand for industrial competitive intelligence in the context of innovation-driven development, which has good feasibility. We can systematically and comprehensively grasp the whole process of innovation and development of the genetic engineering vaccine industry.

Through further in-depth analysis, we established that Jie Zhang's research is focused on technological innovation, Hongqi Wang is focused on scientific and technological innovations, industrial innovations, and innovation ecosystems, while Chao Wang is focused on industrial competitive intelligence. Table 3 shows studies with high co-citations with regard to industrial competitive intelligence. The research interests of Haiyun $\mathrm{Xu}$ are in the theory and practice of information metrology, and his main areas of focus are scientific and technological innovation, information science, and industry-universityresearch cooperation, among others. We found that major scholars in the field of innovation chain did not specifically specialize in the field of innovation chain but mentioned the concept of innovation chain or had some correlation with it in their papers. According to a detailed literature search, Zhibiao Liu and Zhong Yang were found to have made significant contributions in the field of innovation chain research in recent years. However, based on CiteSpace analysis, Zhibiao Liu and Zhong Yang rank fifth and tenth, respectively. Zhibiao Liu [7] reported that "Under the growth model of manufacturing industry based on global value chain, the impetus of China's industrial development is declining. Entering the transition period of the new normal, China must shift from joining the global value chain to being embedded in the global innovation chain". Zhong Yang [8] analyzed the concept and connotation of the innovation chain and elucidated on the future research direction of the innovation chain. 
Table 3. Detailed table of Chinese author paper outputs on innovation chain.

\begin{tabular}{ccccccc}
\hline Author & Number & Burst & Grade & Centrality & From Time & Half-Life \\
\hline Jie Zhang & 10 & & 4 & 0 & 2017 & 2.5 \\
Hongqi Wang & 6 & & 9 & 0 & 2012 & 1.5 \\
Chao Wang & 5 & 2.69 & 5 & 0 & 2017 & -0.5 \\
Haiyun Xu & 5 & 2.69 & 5 & 0 & 2017 & -0.5 \\
Zhibiao Liu & 5 & & 2 & 0 & 2012 & 2.5 \\
Shu Fang & 4 & & 3 & 0 & 2017 & 0.5 \\
Jianlong Wu & 4 & & 5 & 0 & 2012 & 1.5 \\
Ping Li & 4 & & 7 & 0 & 2014 & 0.5 \\
Xuejun Lin & 4 & & 4 & 0 & 2018 & -0.5 \\
Zhong Yang & 4 & & 5 & 0 & 2019 & 0.5 \\
\hline
\end{tabular}

\subsection{Analysis of Domestic Research Hotspots}

The 459 downloads from CNIC were imported into Citespace.V.5.7R2. Cluster node type attribute was selected as the Keyword, while the threshold value was set as TOP50 to obtain network analysis results of innovation chain keywords. A ring-style figure can express more information. In the knowledge map of node structure, keywords are referenced by rings; different colors represent different years. The growth ring size indicates the citation frequency of the concept. The larger the growth ring, the higher the citation frequency; the smaller the growth ring, the lower the citation frequency. The radius of the node corresponds to the total citation number of the node.

As shown in Figure 2, the top ten keywords in terms of occurrence frequency were: innovation chain (113), industrial chain (37), collaborative innovation (27), scientific and technological innovation (14), innovation-driven (14), technological innovation (14), strategic emerging industries (13), Beijing-Tianjin-Hebei (11), innovation ecosystem (10), and integration of industry and education (9). Among these keywords, technological innovation (4.36), strategic emerging industry (4.34), technological innovation chain (2.55), innovationdriven (3.46), and integration of industry and education (3.02) had higher emergent values (Figure 3). Clustering around all keywords resulted in 73 . The main 12 clusters were: \#0 innovation chain, \#1 innovation ability, \#2 double cycle, \#3 integration of production and education, \#4 technological innovation, \#5 manufacturing industry, \#6 transformation of scientific and technological achievements, \#7 high-quality development, \#8 global supply chain, \#9 Internet technology, \#10 risk contagion, and \#11 resource integration.

In CiteSpace, keywords with the strongest citation bursts denote the frontier of research in a particular field. Emergent detection of keywords in a time series was obtained based on a knowledge graph of keyword research hotspots, as shown in Figure 3. From 2010 to 2015, the burst keyword was "technological innovation", with a burst intensity of 4.36. Studies have analyzed the role of technological innovation in industrial innovation from an innovation chain perspective [9]. From 2011 to 2014, emergent keywords were "strategic emerging industries" and "technological innovation chain", with emergent intensities of 4.34 and 2.55, respectively. Yipeng Huang proposed the construction of a patent alliance and standardization strategy based on balanced decision-making mechanisms between technological and collaborative innovations in the development of strategic emerging industries [10]. Shaobo $\mathrm{Wu}$ reported that the knowledge innovation chain is a cooperative partnership composed of core enterprises and upstream as well as downstream $R \& D$ organizations with technical supporting functions. Moreover, it is an important way for strategic emerging industries to realize collaborative innovations [11]. From 2016 to 2017, the burst keyword was "innovation-driven", with a burst strength of 3.46. Dongdong Liu in their paper-“"Embedment of Global value chain, Innovation drive and Upgrading of Chinese manufacturing industry" - proposed that embedding the global value chain position will influence process upgrading and product upgrading in manufacturing industries through the innovation-driven effects of imports of intermediate goods and foreign investments [12]. From 2018 to 2020, the burst keyword was "integration of industry and 
education", with a burst intensity of 3.02. Scholars have analyzed internal correlations among "education chain, talent chain, industrial chain and innovation chain" from the perspective of network links and explored organic linkages of "four chains" to promote industrial and educational integration [13].

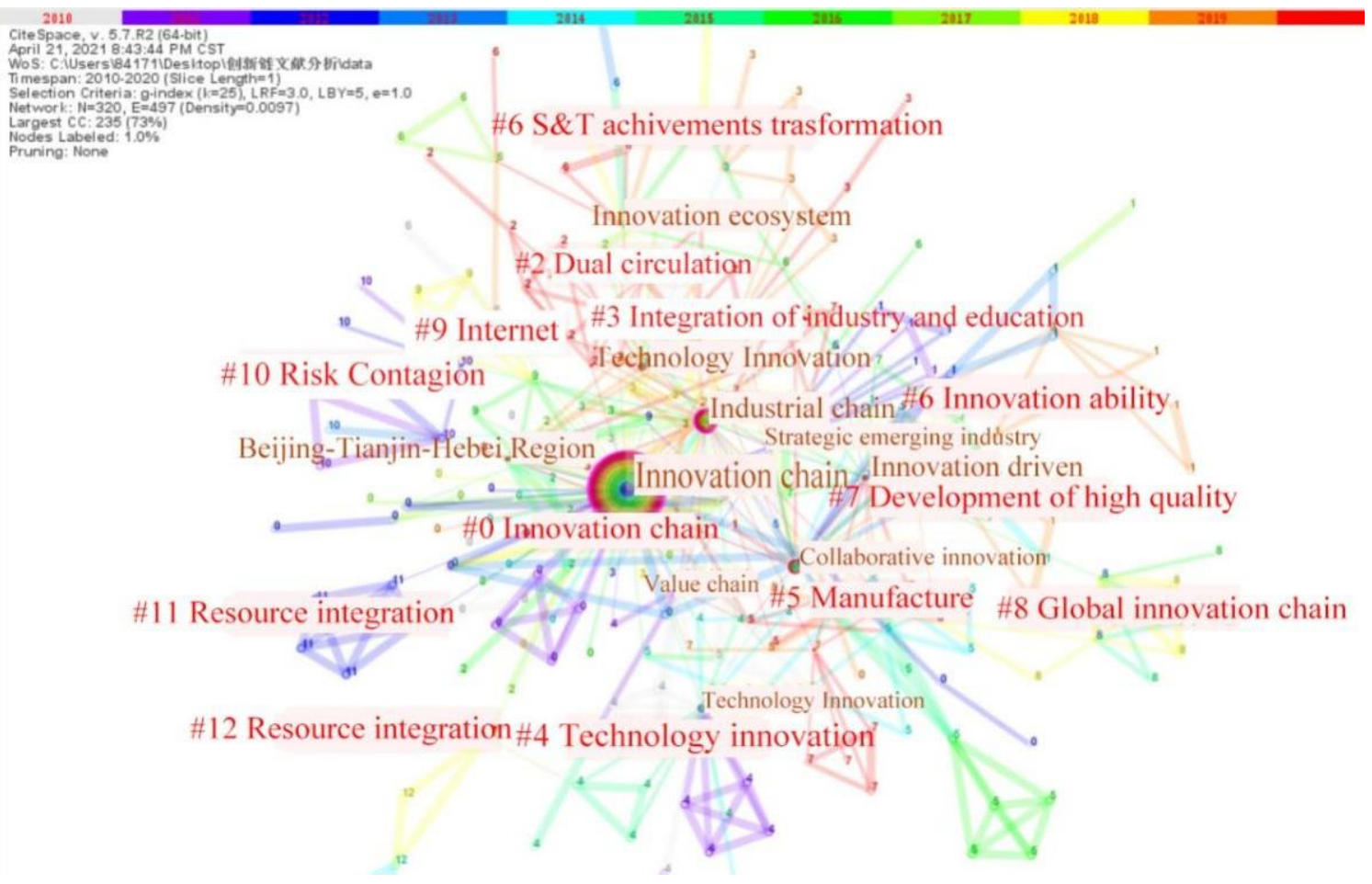

Figure 2. Knowledge map of hot research topics in the innovation chain domain.

\section{Top 5 Keywords with the Strongest Citation Bursts}

\begin{tabular}{|c|c|c|c|c|c|}
\hline Keywords & Year & Strength & Begin & End & $2010-2020$ \\
\hline Technology innovation & 2010 & 4.36 & 2010 & 2015 & \\
\hline Strategic emerging industry & 2010 & 4.34 & 2011 & 2014 & \\
\hline Technology innovation chain & 2010 & 2.55 & 2011 & 2014 & \\
\hline Innovation driven & 2010 & 3.46 & 2016 & 2017 & \\
\hline tegration of industry and education & 2010 & 3.02 & 2018 & 2020 & \\
\hline
\end{tabular}

Figure 3. Emergent detection of keywords in the time series.

\subsection{Network Analysis of Important International Core Journals}

The 5646 downloads from the WOS database were imported into CiteSpace.V.5.7R2 for comprehensive analysis (Figure 4). As shown in the data distribution curve with the innovation chain as the theme from 2010 to 2020, with the passage of time, an increasing number of studies have been conducted in this field. The number increased from 207 in 2010 to 1073 in 2020. Among the 5646 publications, 1 paper was repeated while 504 papers were reviewed. Therefore, a total of 505 publications were deleted, and the remaining 5141 papers were included in the study. 


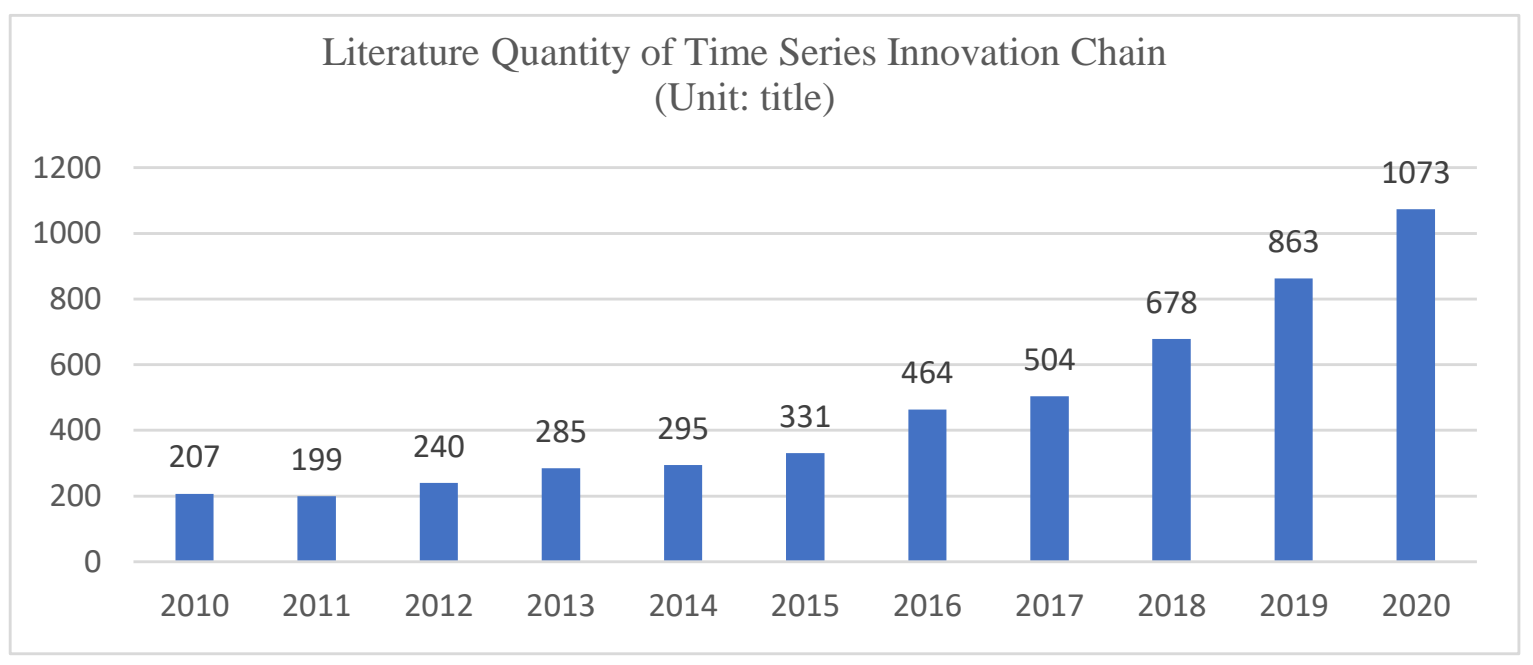

Figure 4. Data distribution curve of innovation chain from 2010 to 2020.

First, a co-citation analysis was performed. The cluster node type attribute was selected as the Reference\&Cite Journal, and the threshold value was set as Top30 to establish the cocitation map of important core journals (Figure 5). In the network diagram, $\mathrm{N}=77, \mathrm{E}=490$, Density $=0.1675$, and important periodicals are relatively concentrated. Table 3 shows that articles with high co-citation frequencies in the field of international innovation chain are from: Journal of Cleaner Production (Q1 subdivision, impact factor 7.246); International Journal of Production Economics (Q1, impact factor 5.134), International Journal of Production Research (Q1, impact factor 4.577), Research Policy (Q1, impact factor 5.351), Sustainability (Q2, impact factor 2.576), Journal of Business Research (Q1, impact factor 4.874), Journal of Operations Management (Q1, impact factor 4.673), Technological Forecasting and Social Change (Q1, impact factor 5.846), International Journal of Operations and Production Management (Q1, impact factor 4.619), and Supply Chain Management and International Journal (Q1, impact factor 4.725). The main research themes of these journals are: management science, economy, business, and operation research, which indicates that these journals have a pivotal position in the field of innovation.

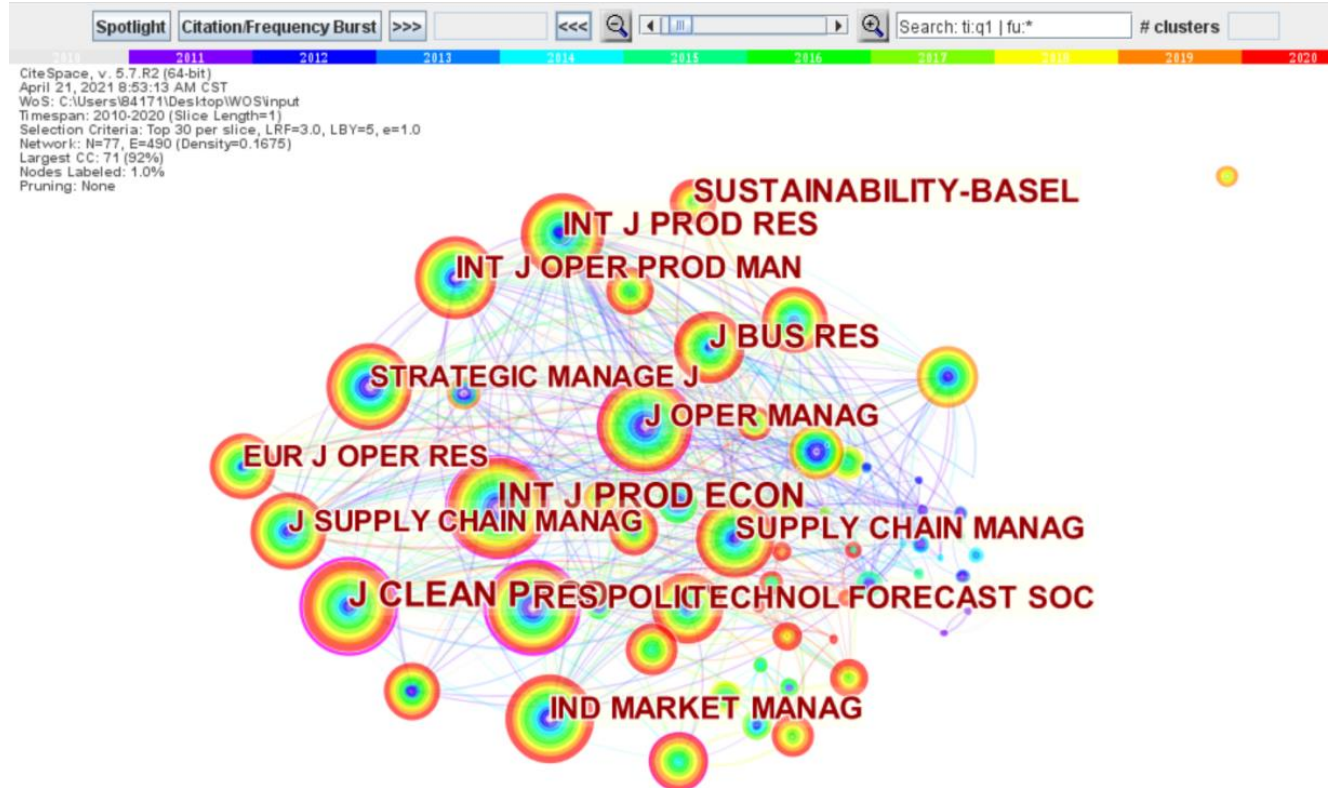

Figure 5. Co-citation network map of research journals in the innovation chain domain. 
As shown in Table 4 and Figure 5, the Journal of Cleaner Production, Research Policy, Journal of Operations Management, and the International Journal of Production and Economics have high centralities, which are $0.24,0.24,0.17$, and 0.11 respectively, indicating that these journals have a high influence on the international community.

Table 4. Citation frequency and related indices of important journals.

\begin{tabular}{|c|c|c|c|c|c|c|}
\hline Frequency & Burst & Degree & Centrality & Journal & Half-Life & Year \\
\hline 1469 & & 30 & 0.24 & J. CLEAN PROD. & 12.5 & 2006 \\
\hline 1286 & & 34 & 0.11 & INT. J. PROD. ECON. & 10.5 & 2007 \\
\hline 747 & & 30 & 0.08 & INT. J. PROD. RES. & 10.5 & 2007 \\
\hline 718 & & 21 & 0.24 & RES. POLICY & 9.5 & 2007 \\
\hline 672 & & 9 & 0.01 & SUSTAINABILITY-BASEL & 3.5 & 2015 \\
\hline 666 & & 24 & 0.06 & J. BUS. RES. & 12.5 & 2006 \\
\hline 659 & 18.93 & 35 & 0.17 & J. OPER. MANAG. & 8.5 & 2007 \\
\hline 643 & & 13 & 0.04 & TECHNOL. FORECAST. SOC. & 9.5 & 2009 \\
\hline 606 & & 25 & 0.06 & INT. J. OPER. PROD. MAN. & 11.5 & 2006 \\
\hline 599 & & 24 & 0.07 & SUPPLY. CHAIN MANAG. & 8.5 & 2008 \\
\hline
\end{tabular}

\subsection{Analysis of Important Foreign Authors}

Co-citation analysis was performed for important authors in the literature. To obtain the co-citation map of important authors, cluster node type attributes were selected as Reference\&Author with threshold values set as TOP30 (Figure 6). In the network figure, $\mathrm{N}=344, \mathrm{E}=1304$, Density $=0.0221$. According to the number of citation frequencies, typical node authors were Yin RK (2017), Ghisellini P (2016), Bocken NMP (2014), Zailani S (2015), Geissdoerfer M (2017), Klewiz J (2014), and Boons F (2013) among others.

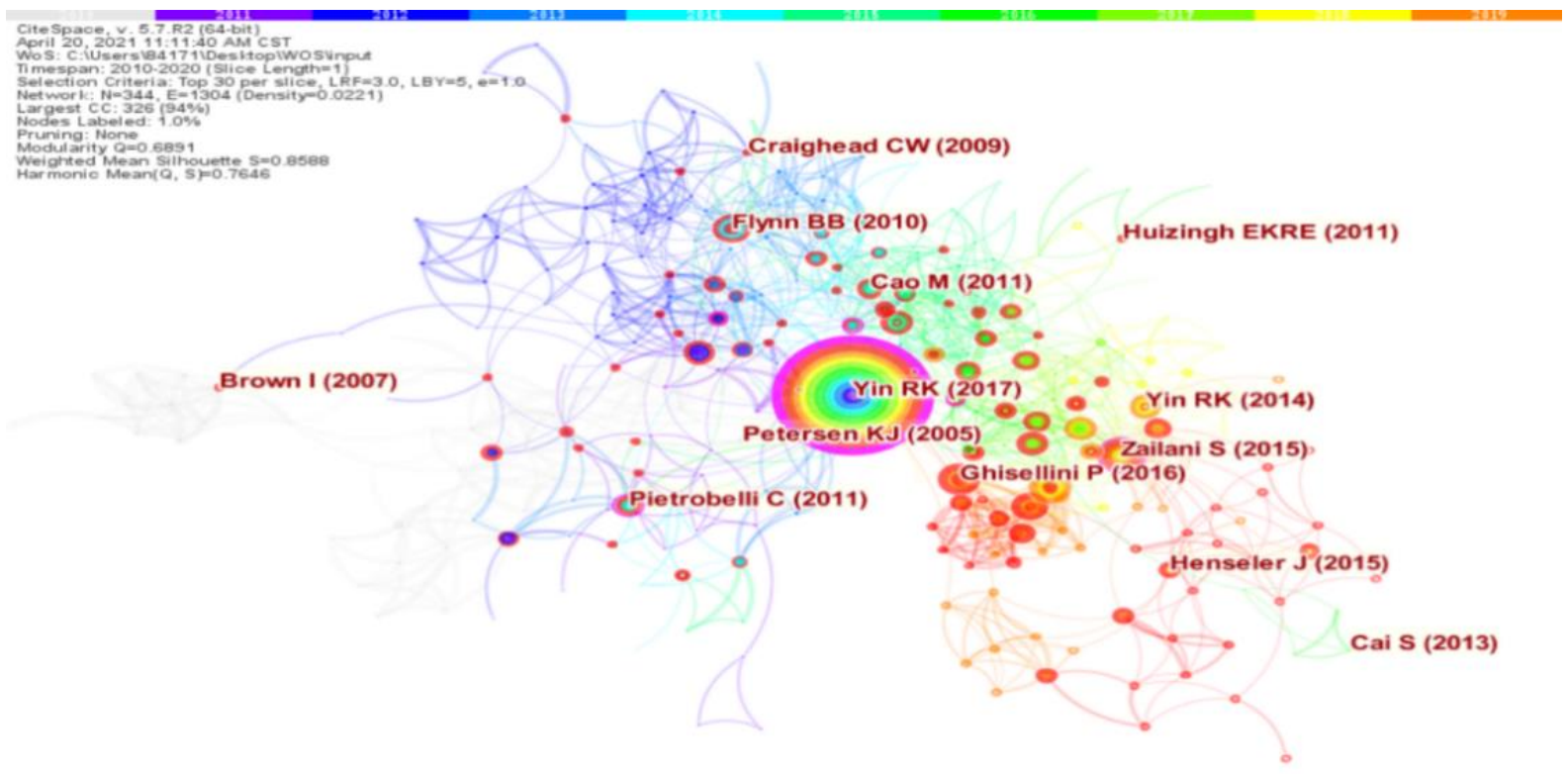

Figure 6. Author analysis of key studies on innovation chains.

Citation parameters of studies with high-frequency words are shown according to the analysis diagram of the main authors in the innovation chain study (Table 5). The book Case Study Research and Applications: Design and Methods compiled by Yin Rk has the highest co-citation frequency, which has been published in its fifth edition and has been cited a total of 215 times. Second, Ghisellini P wrote "A Review on Circular Economy: The Expected Transition to a Balanced Interplay of Environmental and Economic Systems" [14]; Professor Bocken NMP of Cambridge University published the paper "A Literature and Practice 
Review to Develop Sustainable Business Model Archetypes" [15] in 2014, and it has been cited 56 times. In 2015, Professor Zailani S from the University of Malaysia published the paper "Barriers to Green Innovation Initiatives Among manufacturers: the Malaysian case" [16] which has been cited 54 times. Geissdoerfer M from The University of Cambridge published the paper "The Circular Economy-A New Sustainability Paradigm" [17], which has been cited 48 times. Table 5 shows that the citation frequency ( 215 times) and the central value (0.78) of Yin Rk's book-Case Study Research and Applications-are highest, but its half-life is -0.5 . It is unreasonable. With our further analysis, we found that this book is a monograph on case investigation and applications. Since its first printing in 1984, it has been published a total of five times.

Table 5. Cited parameters of high-frequency literature.

\begin{tabular}{cccccccc}
\hline Year & Freq & Burst & Degree & Centrality & Author & Half-Life & $\sum$ \\
\hline 2017 & 215 & & 42 & 0.78 & Yin RK & -0.5 & 1.0 \\
2016 & 59 & 11.74 & 26 & 0.09 & Ghisellini P & 2.5 & 2.83 \\
2014 & 56 & 15.77 & 22 & 0.06 & Bocken NMP & 3.5 & 2.54 \\
2015 & 54 & & 26 & 0.15 & Zailani S & 3.5 & 1.0 \\
2017 & 48 & 12.96 & 21 & 0.01 & Geissdoerfer M & 1.5 & 1.08 \\
\hline
\end{tabular}

\subsection{Analysis of Foreign Research Hotspots and Frontiers in the Field of Innovation Chain}

Through co-citation analysis of keywords, research hotspots and fronts in this field were obtained. First, keyword co-citation analysis was conducted on 5646 publications. To obtain the network diagram of co-citation of important keywords, the cluster node type attribute was selected as Keyword\&Reference, and the threshold value was Top30 (Figure 7). In this network figure, $\mathrm{N}=62, \mathrm{E}=228$, Density $=0.1206$, Largest CC:62 $(100 \%)$. Co-citation frequencies of keywords were: innovation (2162 times), performance (671 times), management (766 times), impact (753 times), supply chain (679 times), supply chain management (643 times), model (526 times), sustainability (505 times), and technology (490 times) among others. Clustering of these high-frequency words formed five clusters (Figure 7). \#0 global value chain $(\mathrm{S}=0.758)$, \#1 blockchain $(\mathrm{S}=0.543)$, \#2 strategy $(\mathrm{S}=0.842)$, \#3 sustainability $(\mathrm{S}=0.597)$, and \#4 absorptive capacity $(\mathrm{S}=0.742)$. Contour values of the clustering region were $>0.5$, and clustering results were very convincing. These findings show that foreign research topics in the field of innovation chain are mainly focused on the global value chain, blockchain, strategic analysis, sustainable development, and absorptive capacity.
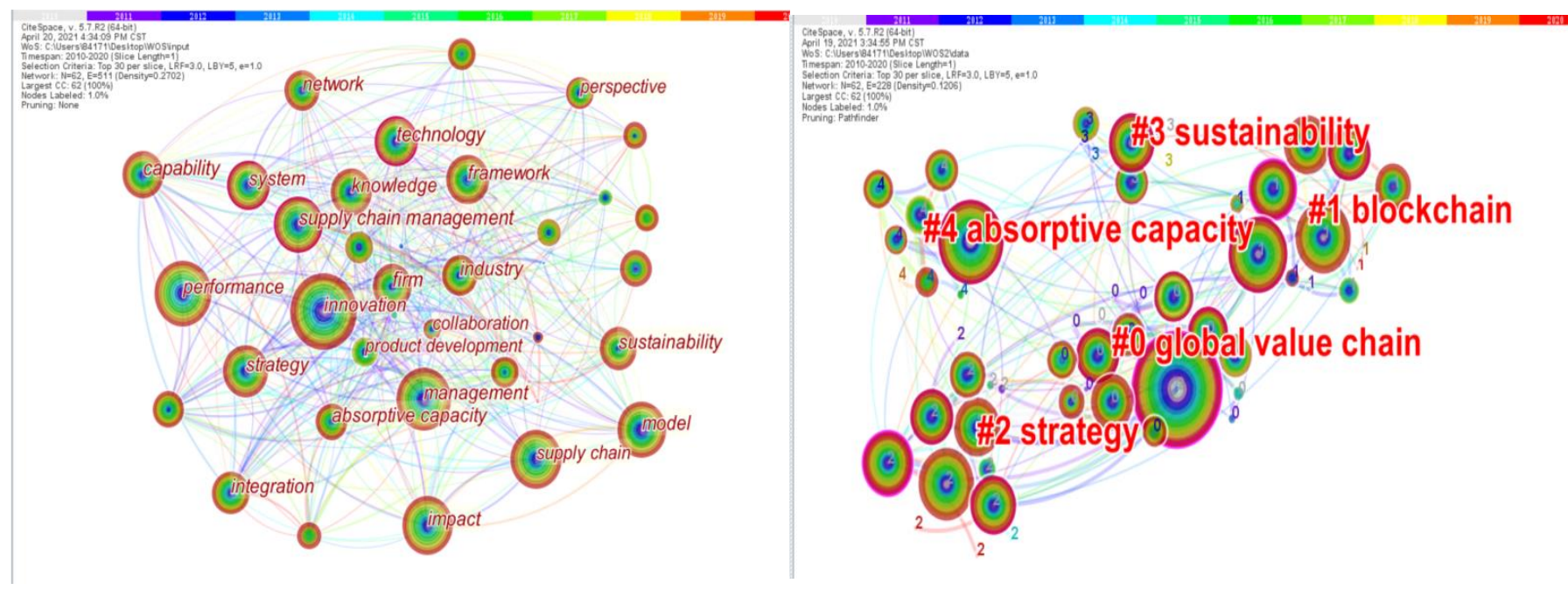

Figure 7. Keywords: literature co-citation; cluster diagram. 
Research frontier of a certain field refers to emerging theoretical trends and the emergence of new topics, which can be considered as one or more topics of common concern to experts and scholars in this field [18]. Theme co-citation results can be used to discuss frontier issues in certain fields, especially in the analysis of cited frequencies of topics and detection of burst values of the topic. Therefore, subject co-citation analysis was performed on 5646 publications. Cluster node type attribute was selected as Term\&Reference, and the threshold value was TOP30. Through clustering, we obtained the theme co-citation cluster diagram, as shown in Figure 7.

Figure 8 shows that $\mathrm{N}=344, \mathrm{E}=1304$, Density $=0.0221$, Largest CC:526 (94\%), Modularity $Q=0.6891$, Silhouette $S=0.858$, Harmonic Mean $(Q, S)=0.7646$. Generally speaking, Modularity: clustering module value $(Q$ value); $Q>0.3$ means clustering structure is significant; Silhouette ( $\mathrm{S}$ value): the average contour value of clustering, with $\mathrm{S}>0.5$ meaning clustering is reasonable and $S>0.7$ meaning clustering is convincing. Therefore, the thematic and literature co-reference cluster diagram is significant. The main frontier clusters were: \#0 Communication Technologies, \#1 Sustainable Operations Management, \#2 Technological Change, \#3 Eco-Innovation, \#4 Supply Chain Integration, \# 5 Industry 4.0, \# 6 Logistics Innovation, \#7 Nanotechnology, \#8 Circular Economy, and \#9 Supply Chain Innovation. These findings show that the current international frontier issues on the innovation chain are mainly concentrated in communication technology, continuous operation management, technological change, ecological innovation, supply chain integration, Industry 4.0, logistics innovation, nanotechnology, circular economy, supply chain innovation, and other related fields [19].

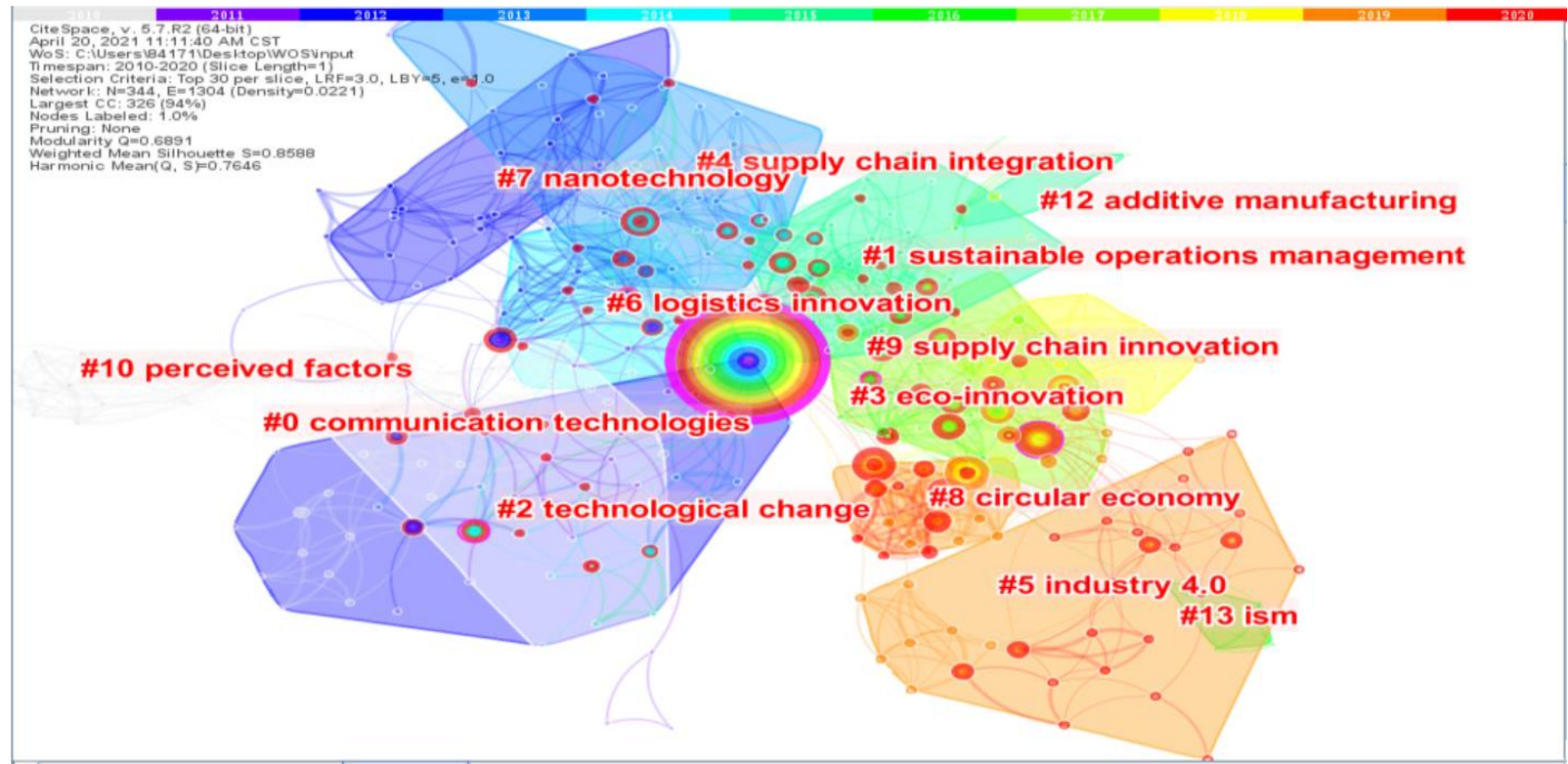

Figure 8. Topic: literature co-citation cluster diagram.

\section{Summary and Outlook}

\subsection{Chinese Research Conclusions}

(1) There were 759 nodes in the map of key authors, with a density of 0.0024 . Although there are a few scholars in the field of innovation chain, there are not many papers written by each scholar in this field. The prolific authors were Jie Zhang (10 times), Wang Hongqi (6 times), Chao Wang (5 times), Xu Haiyun (5 times), Zhibiao Liu (5 times), Shu Fang (4 times), Jianlong Wu (4 times), Ping li (4 times), Xuejun Lin (4 times), and ZhongYang (4 times). This information shows that innovation chain research in China is still in the early stages. In addition, the layout of author nodes was relatively scattered 
while density was low, and therefore, it was hard to form clusters. There is a need to strengthen academic cooperation to improve research on innovation chains.

(2) From the keyword network analysis map of the innovation chain, we found that the Chinese research hotspots were: innovation chain [20], industrial chain, collaborative innovation, scientific and technological innovation, innovation-driven, technological innovation, strategic emerging industries, innovation ecosystem [21], and integration of industry and education, among other fields. These findings show that in the current environment, as far as China's innovation is concerned, technological innovation is key [22], and enterprises should give full play to the driving force of innovation, actively develop strategic new industries, and improve overall competitiveness.

Even though most Chinese research focuses on the "innovation chain", in the current unstable international competition environment, trade protectionism and unilateralism have a huge impact on China's position in the global industrial chain, especially for China's "KEY technologies" in some core technology fields [23]. The importance of technological innovation was emphasized, and there is a need to make full use of existing resources, establish an effective production alliance for high-quality products, and promote our country's enterprise to participate in the high-end global value chain [24]. At the same time, we should pay attention to risk contagion in the innovation process.

\subsection{Conclusions from International Studies}

(1) Most academic studies on the innovation chain have been published in the Journal of Cleaner Production, International Journal of Production on Economics, International Journal of Production Research, Research Policy, Sustainability, and Journal of Business Research, among others. The main research themes of these journals are production, operation, management science, and economy, among others. These findings show that the innovation chain has received attention from multiple disciplines, and, therefore, it belongs to an interdisciplinary research field. Studies from different fields have analyzed the innovation chain from their own research perspectives [25]. Therefore, current research outcomes on the innovation chain are difficult to unify [26].

(2) The most important authors and key studies were analyzed. According to the cocitation map, studies on the "innovation chain" with high co-citation frequencies were Case Study Research and Applications: Design and Methods, "A review on circular economy: The expected transition to a balanced interplay of environmental and economic systems", "A literature and practice review to develop sustainable business model archetypes", "Barriers to green innovation initiatives among manufacturers: the Malaysian case", and "The circular Economy-A new sustainability paradigm". These are not studies on the innovation chain, but they have the innovation chain as a theme or a concept, without in-depth research on the innovation chain [27].

(3) Through co-citation and cluster analysis of the "innovation chain" as a keyword from 2010 to 2020, research hotspots and frontiers in this field were established. We found that foreign studies on the "innovation chain" are more focused on the global value chain [28], blockchain technology, strategic analysis, sustainable development [29], and absorptive capacity, among other fields. Research frontier themes were mainly communication technology, continuous operation management [30], technological change, ecological innovation, supply chain integration, Industry 4.0, logistics innovation, nanotechnology, circular economy, and supply chain innovation [31], among other fields. Therefore, international scholars focus more on: technological issues related to innovation, using advanced communication technology, blockchain technology, and nanotechnology to improve innovation abilities. Moreover, they insist on sustainable development in the process of innovation, advocating for green innovation and ecological innovation [32].

\subsection{Outlook}

The present analysis reveals that significant research has been conducted on the innovation chain. However, there are gaps that require further quantitative analysis of the innovation 
chain field [33]. In addition, the multidisciplinary innovation chain has received increased attention from scholars [34]. It has a production of science, management science, economics, etc. It belongs to the cross-subject, with different scholars from different research perspectives on the innovation chain [35]. The Use of the innovation chain is the profile analysis of the research field; therefore the research on the innovation chain is not thorough, and there is a need to strengthen the cooperation between academic scholars of different subjects and jointly promote the innovation chain. Finally, the focus and frontier of the innovation chain are more about innovation than "chain". The innovation chain has typical characteristics of knowledge fluidity and process. Therefore, the research on the structure and knowledge fluidity of "chain" in the innovation chain needs to be further refined.

Author Contributions: Conceptualization, R.L. and Y.G.; methodology, Y.G.; software, Y.G.; validation, Y.G., R.L. and Y.L.; formal analysis, Y.G.; investigation, Y.G.; resources, Y.G.; data curation, Y.G.; writing—original draft preparation, Y.G.; writing—review and editing, Y.L.; visualization, Y.G.; supervision, R.L.; project administration, R.L.; funding acquisition, R.L. All authors have read and agreed to the published version of the manuscript.

Funding: This research was funded by [Laboratory for Economic Behaviors and Policy Simulation] grant number [71772096]. And The APC was funded by [the National Natural Science Foundation of China].

Institutional Review Board Statement: Not applicable.

Informed Consent Statement: Not applicable.

Data Availability Statement: The data can be downloaded from CNKI and WOS.

Conflicts of Interest: The authors declare no conflict of interest.

\section{References}

1. Li, J.; Chen, C. CiteSpace: Scientific Text Mining and Visualization; Beijing University of Economics and Business Press: Beijing, China, 2016; Volume 2.

2. Chen, C. IBEKWE-SANJUAN, FIDELIA HOU JIANHUA. The structure and dynamics of cogitation clusters: A multipleperspective co-citation analysis. J. Am. Soc. Inf. Sci. Technol. 2010, 61, 1386-1409. [CrossRef]

3. Zhang, J. Pzotential growth rate of structural economy: Theoretical reconstruction, overall judgment and reform direction. $J$. Nanjing Univ. 2020, 57, 38-55.

4. Li, Y.; Zhou, Y.; Wang, H.; Yu, L. Review and prospect of the integration of industrial innovation chain and service chain. Sci. Manag. Res. 2018, 36, 25-27.

5. Wang, C.; Xu, H.; Dong, K.; Fang, S. Analysis framework and Application of industrial competitive intelligence based on innovation chain: A case study of Genetic engineering vaccine industry in China. Inf. Theory Pract. 2018, 41, 87-93.

6. Wang, C.; Dong, K.; Xu, H.; Fang, S. Research on the demand and service strategy of industrial competitive intelligence in the context of innovation-driven development. Mod. Inf. 2017, 37, 16-23.

7. Liu, Z. From global value chain to global innovation chain: A new driving force for China's industrial development under the New Normal. Acad. Mon. 2015, 47, 5-14.

8. Yang, Z.; Li, J.; Wu, Q. Research on innovation chain: Connotation, Effect and direction. J. Nanjing Univ. 2019, 56, 62-70, 159.

9. Liu, Z.; Yao, Z.; Wu, L. Research on strengthening China's division of labor in the process of global industrial chain restructuring. Economist 2020, 4, 51-57.

10. Huang, Y.; Wei, G.; Li, H. A study on strategic emerging Industry's exclusive alliance and standardization strategy. Science and Technology. Sci. Manag. Res. 2013, 33, 170-173.

11. Wu, S.; Gong, Y.; Liu, D. Research on collaborative innovation of strategic emerging industries from the perspective of knowledge innovation chain. Sci. Technol. Prog. Countermeas. 2014, 31, 50-55.

12. Liu, D.; Xie, H.; Zheng, S. Global value chain embedment, innovation driving and China's manufacturing upgrading. J. Int. Bus. Econ. 2021, 3, 17-32.

13. Zhang, Q.; Gu, Y. Link and synergy: The internal logic of the "Four Chains" of industry-education integration. J. Natl. Inst. Educ. Adm. 2021, 4, 48-56.

14. Ghisellini, P.; Cialani, C.; Ulgiati, S. A review on circular economy: The expected transition to a balanced interplay of environmental and economic systems. J. Clean. Prod. 2016, 114, 11-32. [CrossRef]

15. Bocken, N.M.P.; Short, S.W.; Rana, P. A literature and practice review to develop sustainable business model archetypes. J. Clean. Prod. 2001, 2, 42-56. [CrossRef]

16. Abdullah, M.; Zailani, S.; Iranmanesh, M. Barriers to green innovation initiatives among manufacturers: The Malaysian case. Rev. Manag. Sci. 2016, 10, 683-709. [CrossRef] 
17. Geissdoerfer, M.; Savaget, P.; Bocken, N.M.P. The Circular Economy A new sustainability paradigm? J. Clean. Prod. 2017, 2, 757-768. [CrossRef]

18. Su, D.; Wu, Z.; Liu, C. The Research Trend and Research Frontiers of International Technological Innovation Based on Knowledge Map. Sci. Technol. Prog. Countermeas. 2016, 33, 148-155.

19. Tan, J.; Zhang, H.; Lin, R. Simulation and case study on dynamic Evolution mechanism of industrial innovation network. J. Manag. Sci. 2019, 22, 1-14.

20. Shi, L.; Jiang, X. Innovation chain: An integrated analysis framework based on process perspective. Sci. Res. Manag. 2020, 41, 56-64.

21. Chen, Y.; Chen, C.; Hu, Z; Wang, X. Principles and Applications of Analyzing a Citation Space; The Science Press: Beijing, China, 2014; pp. 17-18.

22. Zhang, J.; Ji, Z.; Gao, D. The formation, obstacles and breakthrough paths of the new pattern of "state advancing and people advancing" in China's innovation chain. Econ. Theory Econ. Manag. 2017, 6, 5-18.

23. Liu, Z. The high-end of strategic emerging industries: An economic analysis based on "chain". Ind. Econ. Res. $2012,3,9-17$.

24. Ding, X.; Yang, Z. Visualization of knowledge graph of innovation chain in Chinese context: A bibliometric analysis based on CNKI database. Sci. Technol. Manag. Res. 2020, 40, 10-18.

25. Wen, X.; Li, Y. Innovative study on the performance, cause and continuation path of chain cracks. Sci. Technol. Prog. Countermeas. 2014, 31, 157-160.

26. Zhan, R.; Wang, H.; Meng, X. Review and prospect of enterprise innovation ecosystem. J. Sci. Technol. Manag. 2020, 5, $179-197$.

27. Yu, Y.; Yang, Z. How to effectively leverage the innovation chain function of leading firms: Based on the perspective of new Pasteur Quadrennium of collaborative innovation. Nankai Manag. Rev. 2020, 23, 4-15.

28. Cai, J. Analysis on the connotation and value realization mechanism of industrial innovation chain. J. Tech. Econ. Manag. Res. 2009, 6, 53-55.

29. Chang, A.; Wang, X. Value chain, innovation chain and innovation service chain: A theoretical framework of science and technology intermediary System based on service Perspective. Sci. Manag. Res. 2011, 2, 30-34.

30. Hu, Z.; Nan, J. Industrial technology innovation strategic alliance: The industrial expansion of R\&D strategic alliance. Reform Strategy 2010, 26, 38-41.

31. Li, Y.; Lin, R. The impact of knowledge network structure and cross-border search on organizational breakthrough innovation: An analysis of American artificial intelligence patents. Sci. Technol. Manag. Res. 2020, 40, 204-212.

32. Liu, Z. Promoting supply-side structural reform must optimize and upgrade industrial chain. Economic Information Daily, 3 November 2020, p. 1.

33. Ling, Y.; Liu, Z. The Concept, characteristics and policy implications of domestic demand-oriented global value chain. Economist 2020, 6, 26-34.

34. Zhang, J. New trends and countermeasures of global supply chain evolution under China-USA strategic pattern Exploration and Contention. Explor. Free. Views 2020, 37-52, 198.

35. Zhang, J. Institutional barriers and breakthrough directions of China's key technology innovation. J. Nantong Univ. (Soc. Sci. Ed.) 2020, 36, 108-116. 